\title{
Use of "Weekly goal oriented teaching method" for dental nursing students during the outpatient clinical internship
}

\author{
Wen Liu * \\ Shanghai University of Medicine and Health Sciences, Shanghai, China
}

Received: December 4, 2016

Accepted: March 15, 2017

Online Published: April 9, 2017

DOI: $10.5430 /$ jnep.v7n7p129

URL: https://doi.org/10.5430/jnep.v7n7p129

\begin{abstract}
Background and objective: Given the current rapid development of the profession, great emphasis in dental nursing education is focused on clinical internship training. The aim of this study is to investigate the effects of the "Weekly Goal Oriented Teaching Method" for dental nursing students during their outpatient clinical internship.

Methods: A quasi-experimental study was carried out among students enrolled in the dental nursing major during the 2012 school year. They were randomly divided into two separate study groups according to their scheduled outpatient clinic internship schedule. The students scheduled for their outpatient clinic internship during the first four months (Months 1-4) were placed in the control group. The instructors in the control group utilized conventional teaching methods. Students scheduled during the following four months (Months 5-8) were placed in the experimental group using the "Weekly Goal Oriented Teaching Method". Comparison of both groups included the student's examination scores, student evaluation about the clinical internship training, and the nursing instructor's evaluation of the student's learning experience.

Results: Compared to the control group, the students in the experimental group had examination scores that were statistically significant higher in the Department of Oral and Reconstructive Surgery, Orthodontics, and the Four-Hand Operation Department $(p<.05)$. The student evaluation of the clinical internship in the experimental group significantly surpassed the student evaluation in the control group in the areas of internship planning, teaching methods, and student-teacher communication $(p<.05)$. The clinical nursing instructor's teacher evaluation scores given to the students in the experimental group surpassed the evaluation scores for students in the control group in the fields of technical learning skills, and communication skills $(p<.05)$.

Conclusions: The use of the "Weekly Goal Oriented Teaching Method" can improve and promote acquiring the essential professional skills and knowledge, enhance internship planning, improve teaching methods, and strengthen teacher-student communication. In addition, the "Weekly Goal Oriented Teaching Method" can emphasize principles of nursing theory and compassionate care.
\end{abstract}

Key Words: Weekly goal oriented teaching method, Dental nursing, Outpatient clinic internship

\section{INTRODUCTION}

As the dental nursing profession develops, increased demands are placed on the nurse to master new technical skills. Given the current rapid development of the profession, great emphasis in dental nursing education is focused on clinical internship training. ${ }^{[1,2]}$ Compared to traditional nursing, dental nursing is a more specialized field of nursing. These distinguishing features include a larger patient volume in

*Correspondence: Wen Liu; Email: 359956896@qq.com; Address: Shanghai University of Medicine and Health Sciences, Shanghai, China. 
the outpatient dental clinics, increased ability to perform nursing technical skills, more diversified nursing role, and newer technology and faster development in the profession. Not only is it necessary for the dental nurse to ensure patient satisfaction, but also to satisfactorily provide assistance to the dentist in the course of his work. ${ }^{[3]}$ The quality of teaching during the clinical internship has a direct impact on the overall quality of education and is given the highest priority of importance during the student's vocational training. Nevertheless, the currently accepted clinical practice training methods and structure still have room for improvement. Presently in China, research efforts in dental nursing internship teaching methods are still in the beginning stages of development. Consequently, this research has a relevant impact in developing an evidence-based model for effective teaching methods during the internship experience that address the specialized features of the outpatient clinic setting. The purpose of this research is to provide a foundation for nursing instructors and managers to formulate a systematic teaching plan in accordance to the necessary nursing job requirements, improve the quality of clinical internship training, enhance the clinical internship experience and further promote the dental nursing profession.

\section{RESEARCH SUBJECTS AND METHODS}

\subsection{Research subjects}

During the 2012 school year, all students enrolled in their senior year in the dental nursing program at the Shanghai Institute of Health Sciences represented the study sample totaling 48 students. Every dental nursing student in their senior year participates in an 8 month internship which is equally divided into two four month assignments. One four month assignment is in the hospital setting and the other four month assignment is in the outpatient clinic setting. All students assigned to the outpatient clinic internship were randomly divided into two study samples. The students assigned to the outpatient clinical internship during the first four months (Months 1-4) served as the control group. During the next four months (Months 5-8) the outpatient clinic internship students served as the experimental group. Both of the study groups shared the same outpatient clinic internship schedule in rotating through six different departments which included: Dental Medicine, Dental Surgery, Prosthodontics, Four-Hand Treatment Operation, Orthodontics, and Periodontal Medicine. The experimental study group was taught using the "Weekly Goal Oriented Teaching Method" and compared to the control group taught by conventional internship teaching methods. Both the experimental and control study groups had an identical rotation schedule through each of the six outpatient clinic departments.
The experimental study group sample included a total of 24 students. Among the 24 students, fourteen students were Shanghai residents $(58.3 \%)$ and ten students were residents of other provinces in China (41.7\%). During their student career, seven students served as a class monitor $(31.3 \%)$ and seventeen students did not serve in a class monitor role $(68.7 \%)$. Those students who earned a merit scholarship included 8 students $(29.2 \%)$ and students who did not earn a merit scholarship totaled sixteen students (70.8\%). Four students accepted the role as a large group leader during the internship (16.7\%), eight students accepted the role as a small group leader $(33.3 \%)$, and twelve students did not assume any additional leadership responsibilities (50\%). After graduation eight students accepted an employment offer at a general public hospital (33.3\%), eleven students accepted an employment offer at a public dental hospital (45.8\%), and the remaining five students accepted an employment offer at a private outpatient dental clinic $(20.8 \%)$. Concerning the students' general interest in the dental nursing profession, eighteen students expressed positive interest (75\%) and six students conveyed an indifferent attitude or lack of interest in the profession $(25 \%)$. The control study group included a total of 24 students. Among the 24 students in the control group, thirteen students were Shanghai residents (54.2\%) and eleven students were from other provinces in China (45.8\%). During their student career, eight students served as a class monitor $(31.3 \%)$ and sixteen students did not serve in a class monitor role $(66.7 \%)$. Those students who earned a merit scholarship included 7 students $(29.2 \%)$ and students who did not earn a merit scholarship totaled seventeen students (70.8\%). Four students accepted the role as a large group leader during the internship (16.7\%), eight students accepted the role as a small group leader $(33.3 \%)$, and twelve students did not assume any additional leadership responsibilities (50\%). After graduation eleven students accepted an employment offer at a general public hospital (45.8\%), ten students accepted an employment offer at a public dental hospital (41.7\%), and the remaining three students accepted an employment offer at a private outpatient dental clinic $(12.5 \%)$. Concerning the students' general interest in the dental nursing profession, sixteen students expressed positive interest (66.7\%) and eight students conveyed an indifferent attitude or lack of interest in the profession (33.3\%). The demographics of the control and experimental groups did not display any statistically significant differences $(p>.05)$.

\subsection{Study tools and methods}

All the study tools are designed by the researchers themselves, before using them in the study researchers have tested these questionnaires' validity to make sure that these questionnaires have good validity.

ISSN 1925-4040 E-ISSN 1925-4059 


\subsubsection{Subject data}

The data points collected for each student included: age, hometown, merit scholarship status, post-graduation employment plans, internship assignment, internship department rotation schedule, and internship time schedule.

\subsubsection{Clinical teaching feedback questionnaire}

Each student individually completed a Clinical Teaching Feedback Questionnaire. The researcher personally created and drafted this questionnaire after reviewing pertinent and relevant published literature articles. It is concluded that the questionnaire has good reliability and includes a total of six data points: internship plan quality, instructor's teaching capability, teaching methods, teacher-student communication, compassionate care, and overall evaluation.

\subsubsection{Clinical internship evaluation questionnaire}

Each clinical instructor individually completed a Clinical Internship Evaluation Questionnaire. After reviewing pertinent and relevant literature articles, the researcher personally created and drafted this questionnaire. The main goal of the questionnaire is to have the clinical nursing instructors evaluate the nursing students' internship experience. The following data points were included in this questionnaire: Professional qualifications and achievements of the clinical instructor, Professional knowledge and skills of the nursing student, student understanding of the profession, attitude towards learning, and communication ability.

\subsubsection{Teaching method}

The conventional outpatient internship teaching method does not incorporate a pre-determined teaching plan. Instructors provide lectures or demonstrations in a more sporadic style during the internship experience. The convention teaching method includes formal and informal lectures as well as demonstrations. In contrast, the "Weekly Goal Oriented Teaching Method" includes specific teaching objectives, plans and course content designed weekly according to the clinical department skills to be learned during each week of the internship rotation cycle. The necessary skills and knowledge for each clinical department rotation are planned and evaluated on a weekly basis to make necessary adjustments for the next week of clinical internship instruction. Each week through an orderly process the clinical instructors evaluate and make necessary adjustments to the teaching objectives, plan and course content. Before the start of a new week of the student's internship rotation, a complete written teaching objective, plan and course content are formulated. Teaching methods are focused on lectures, case studies, group discussions, simulation skills training, and impromptu clinical discussions. The teaching content of the conventional teaching method and "Weekly Goal Oriented Teaching Method" are similar and encompass common diseases and ailments frequently seen in the outpatient clinical setting. The main objective in both the control and experimental study groups is to teach students to master the fundamental principles of dental nursing care and to understand the common diagnoses, treatments and procedures. The following data was collected for every participant in both study groups: student examination scores, Clinical Teaching Feedback Questionnaire, and Clinical Internship Evaluation Questionnaire. Among the two study groups the same standard of grading and examination criteria were used.

\subsubsection{Statistical methods}

All data was recorded and entered into the computer, then statistically analyzed using the SPSS15.0 software package program.

\section{ReSUlts}

\subsection{Comparison of control and experimental group ex-} amination scores

According to Table 1, the experimental group test scores were statistically significant different in the following clinical departments: Prosthodontics, Four Hand Operation Treatment and Orthodontics $(p<.05)$. There was no statistical difference in the examination scores in comparing both groups in the following clinical departments: Dental medicine, Dental surgery, and Periodontal Medicine $(p>.05)$.

Table 1. Comparison of control and experimental group examination scores

\begin{tabular}{|c|c|c|c|c|}
\hline \multirow{2}{*}{ Clinical Department } & \multicolumn{2}{|l|}{ Examination Score } & \multirow{2}{*}{$t$} & \multirow{2}{*}{$p$} \\
\hline & Experimental Group & Control Group & & \\
\hline Dental medicine & $90.66 \pm 9.44$ & $89.62 \pm 8.10$ & 3.625 & .322 \\
\hline Dental Surgery & $91.58 \pm 10.01$ & $90.99 \pm 8.46$ & 3.122 & .351 \\
\hline Prosthodontics & $90.70 \pm 9.82$ & $86.28 \pm 7.98$ & 9.962 & $.023 *$ \\
\hline Four Hand Operation Treatment & $92.60 \pm 11.10$ & $86.01 \pm 8.83$ & 11.931 & $.016^{*}$ \\
\hline Orthodontics & $89.95 \pm 9.23$ & $85.23 \pm 9.64$ & 9.233 & $.027 *$ \\
\hline Periodontal Medicine & $89.80 \pm 7.32$ & $88.96 \pm 8.25$ & 4.116 & .236 \\
\hline
\end{tabular}

${ }^{*} p<.05$ 
3.2 Comparison of control and experimental groups perimental group: Internship plan quality, Teaching Method, clinical teaching feedback questionnaire

Teacher-Student Communication, and Evaluation $(p<.05)$.

Table 2 shows a statistically significant difference in a favor- No statistical difference was found between the two groups able result for the following questionnaire fields for the ex- in teaching capability and compassionate care $(p>.05)$.

Table 2. Comparison of control and experimental groups clinical teaching feedback questionnaire

\begin{tabular}{lllllll}
\hline & $\begin{array}{l}\text { Internship } \\
\text { plan quality }\end{array}$ & $\begin{array}{l}\text { Instructor's } \\
\text { Teaching Capability }\end{array}$ & $\begin{array}{l}\text { Teaching } \\
\text { Method }\end{array}$ & $\begin{array}{l}\text { Teacher Student } \\
\text { communication }\end{array}$ & $\begin{array}{l}\text { Compassionate } \\
\text { care }\end{array}$ & $\begin{array}{l}\text { Overall } \\
\text { Evaluation }\end{array}$ \\
\hline Experimental Group & $17.75 \pm 3.58$ & $25.54 \pm 4.09$ & $36.51 \pm 4.88$ & $23.32 \pm 5.79$ & $31.52 \pm 5.21$ & $35.6 \pm 4.43$ \\
Control Group & $11.88 \pm 3.42$ & $24.5 \pm 3.77$ & $28.8 \pm 3.55$ & $18.8 \pm 4.02$ & $32.8 \pm 5.01$ & $29.4 \pm 4.665$ \\
$t$ & 12.761 & 3.232 & 14.778 & 11.386 & 4.332 & 15.225 \\
$p$ & $.012 *$ & .334 & $.009 *$ & $.018 *$ & .231 & $.004 *$ \\
\hline${ }^{*} p<.05$ & & & & &
\end{tabular}

3.3 Comparison of control and experimental groups clinical internship evaluation questionnaire

Table 3 shows a statistically favorable difference in the experimental group compared to the control group in the following fields: Professional qualification of the teacher and communication ability $(p>.05)$. No statistical difference between the two groups was shown in the fields of attitude towards learning and knowledge of the profession $(p<.05)$.

Table 3. Comparison of control and experimental groups clinical internship evaluation questionnaire

\begin{tabular}{lllll}
\hline & $\begin{array}{l}\text { Professional knowledge and } \\
\text { skills of the nursing student }\end{array}$ & $\begin{array}{l}\text { Student understanding } \\
\text { of the profession }\end{array}$ & $\begin{array}{l}\text { Attitude towards } \\
\text { learning }\end{array}$ & $\begin{array}{l}\text { Communication } \\
\text { Ability }\end{array}$ \\
\hline Experimental Group & $32.55 \pm 4.23$ & $17.11 \pm 3.21$ & $15.96 \pm 2.98$ & $17.52 \pm 3.22$ \\
Control Group & $27.02 \pm 4.19$ & $17.80 \pm 4.11$ & $15.66 \pm 2.32$ & $14.69 \pm 3.07$ \\
$t$ & 11.023 & 2.809 & 2.125 & 8.962 \\
$p$ & $.020 *$ & .382 & .412 & $.037^{*}$ \\
\hline$*_{p}<05$ & & &
\end{tabular}

\section{Discussion}

\subsection{Applicability of a goal oriented teaching method in the dental nursing outpatient clinic}

This research study revealed that the teaching plan, methods, and feedback for the experimental group is more favorable compared to the conventional teaching plan used for the control group. Therefore it is clear that the "Weekly Goal Oriented Teaching Method" has high applicability for the dental nursing outpatient clinic internship. Previous investigations have revealed that dental nursing students considered the clinical internship teaching plan and organization inadequate and in need of improvement. ${ }^{[4]}$ For example, informal lectures were not scheduled according to a plan and teaching objectives were unclear. Since the development of the dental nursing profession started relatively late, a systematic clinical teaching method to improve the internship experience has not yet been devised. Establishing a systematic teaching plan in the outpatient setting would further enhance the teaching methods. Clinical teaching remains one of the targeted areas to develop the profession. Another aspect is the difference in the special characteristics of dental outpatient internships compared to inpatient setting. Those differences include: the high volume of patients, high patient turnover rate, more limited appointment and treatment time for the patients, more specialized technical nurse training, diverse nursing role, rapid technological development of the profession. The dental nurse must not only ensure patient satisfaction but also satisfactorily assist the dentist in the course of his work. ${ }^{[5]}$ Given that the dental nurse's work environment is face-paced and intense puts additional constraints of time and energy to devote to teaching and training.

Despite the fast-paced intense working environment, high patient turnover, various diseases and varied treatments used in the outpatient clinic, a systematic plan of teaching and training must be established. Proper teaching objectives and methods should be established to better ensure the nursing student's professional competence after graduation. Compared to the conventional teaching method the "Weekly Goal Oriented Teaching Method" is a more efficient, orderly, and organized teaching plan that is properly adjusted each week. These weekly adjustmented goals and objectives can im- 
prove the quality of education and clarify difficult concepts for the nursing student. By planning in advance a wellorganized and established teaching plan, it is less likely that the usual nursing duties of the clinical instructor will disrupt the student's educational goals and outcomes. Therefore, the "Weekly Goal Oriented Teaching Method" has more clear and obvious advantages.

\subsection{The "Weekly goal oriented teaching method" strengthens student teacher communication}

A significant factor influencing the nursing student's successful training during internship is effective communication and strong working relationship with their nursing instructors. ${ }^{[6]}$ These research findings reveal that for the "Weekly Goal Oriented Teaching Method" the students' questionnaire scores for teacher student communication and overall evaluation are more favorable compared to the scores of the conventional teaching methods. The evaluation of the teaching capability in both study groups did not show any significant difference. Zhu Manqun's ${ }^{[7]}$ research findings indicate that interactive, positive, and dynamic student teacher communication is beneficial to improve the teaching methods. The "Weekly Goal Oriented Teaching Method" especially encourages student teacher interaction and communication. Every week there are many opportunities for teacher student interaction such as, discussing the teaching plan, feedback, evaluation, and carefully making adjustments necessary to further promote the student's level of competence of the internship requirements. One additional benefit of this weekly teaching plan is the possibility of increasing the student's interest, motivation and enthusiasm towards the profession. The student's overall communication ability can become more effective. The ability to resolve problems in a fast-paced environment with time constraints is important preparation and training for practice in the outpatient dental clinic.

\subsection{The "Weekly goal oriented teaching method" em- phasizes a higher level of professional interest}

The nursing student's level of interest towards the profession influences how actively engaged and enthusiastic they are during their course of study. Previous research investigations indicated that nursing students that had a high level of professional interest displayed greater enthusiasm during lecture classes were more motivated to study and achieve greater student success. ${ }^{[4]}$ During this research study the nursing clinical instructors observed no remarkable difference between the two study groups in the students' knowledge of the profession. Comparing general nursing students with dental nursing students, dental nursing students prefer outpatient practice and are more likely to obtain employment in the dental outpatient clinic. The nurses practicing in the dental

Published by Sciedu Press outpatient clinic are not required to work night shifts and their work environment is less intense compared to nursing practice in the inpatient setting. It is not yet clear whether the "Weekly Goal Oriented Teaching Method" is instrumental in improving the level of professional interest since the main objectives of the clinical teaching methods are focused on improving professional knowledge and technical nursing skills. Also, there is a relatively small and no special emphasis on principles of nursing theory in these teaching modules. A number of factors can increase the student's level of enthusiasm towards the profession. Those factors can include: the clinical nursing instructors collaborating together to determine the teaching content and methods, making beneficial changes to the curriculum, increasing the content of nursing theory principles, and proper professional guidance during the internship rotations. In addition, more professional training can be integrated for working nursing professionals at the outpatient clinics.

\subsection{Use of the "Weekly Goal Oriented Teaching Method" can be a significant contributing factor to outstanding results in the dental outpatient clinic}

The "Weekly Goal Oriented Teaching Method" has significant results for the dental outpatient clinic. In the experimental group the overall evaluation was more favorable compared to the control group. The clinical instructors also viewed the experimental student group's grasp of the knowledge and technical skills more favorably compared to the control group. This positive overall evaluation can be attributed to the following reasons: sequential and orderly teaching method, progressive teaching objectives, organized teaching content, timely feedback on the teaching methods, and a teaching method that is suitable for the outpatient clinic working environment.

The experimental group's examination scores in the following departments: prosthodontics, four hand operation treatment and orthodontics surpassed the scores of the control group. In these three departments, compared to other clinical departments, the expertise and technical skill demands of the nurses is higher, the nurses and doctors work more closely together in collaborative practice, have more intensive work demands, and more comprehensive and rigorous teaching content. Therefore, the "Weekly Goal Oriented Teaching Method" is effective to utilize the teaching time, make necessary adjustments based on feedback, and clarify more difficult points of the curriculum for students to understand and grasp the material. This allowed the nursing students to have an overall more effective internship experience. Considering the other three departments students rotated through during their internship, those departments were comparatively less 
intense, the work environment was not as fast-paced, allowed for more teaching time during the internship, and the teaching content was not as rigorous. Consequently, the different teaching methods for the other three departments did not significantly impact the educational quality for the student's successful completion of the internship.

\section{Conclusion}

Presently, the dental outpatient clinic still lacks a rigorous systematic teaching plan for training students and nurses. This research compared the experimental "Weekly Goal Oriented Teaching Method" with conventional teaching methods applied during the dental nursing student's internship. The results showed that the student nurses had a more favorable evaluation of the "Weekly Goal Oriented Teaching Method" compared to the conventional teaching methods. The results further indicated that the experimental teaching method was more effective in teaching the new knowledge and technical skills, and can promote stronger student teacher communication. Regarding teaching compassionate care and principles of nursing theory, there is still room for improvement and development. This investigation contributes to introducing more developments in advancing the teaching methods and clinical preparation of the students, nurses, nursing instructors and nurse managers in the dental outpatient clinic. Not only can this clinical teaching plan provide the basis to improve the professional quality of clinical internship teaching but also further promote the dental nursing profession.

\section{CONFLICTS OF INTEREST Disclosure}

The author declares that there is no conflict of interest.

\section{REFERENCES}

[1] Liu Y. Current growth, development and challenges in the Dental Clinic. Guangdong Dental Prevention and Treatment. 2008; 16: 666667.

[2] Fu MK. Development and Requirements of the Private Dental Medical Organization. Chinese Journal of Dental Treatment. 2004; 39(2): 161.

[3] Feng XH, Wang L, Feng JF, et al. Common Challenges and Solutions for Nursing practicing in the Dental Medicine Department. Armed Forces Medical Science. 2008; 19(9): 850.
[4] Liu W, Chen FZ, Xu XD. Nursing Students (Oral Health) Comparison of Current Teaching Methods in the Outpatient Clinic and Hospital Setting. Health Vocational Training. 2015; 33(10): 7-129.

[5] Zhao FR. Dental Nursing Education. Shanghai: Fudan University Press; 2009. $129 \mathrm{p}$.

[6] Cai PY, Lu P, Zhou YQ, et al. Investigation of an Evidence-Based Dental Nursing Student Clinical Teaching Model. Chinese Journal of Nursing Education. 2008; 5(4): 173-175.

[7] Zhu MQ. Investigation of a Dental Nursing Clinical Teaching Model. Guangdong Dentristy. 2009; 17(12): 603-605. 